\title{
A systematic review of neuropsychiatric and cognitive assessments used in clinical trials for amyotrophic lateral sclerosis
}

\author{
Emily Beswick ${ }^{1,2,4}\left(\right.$ Emily Park $^{3} \cdot$ Charis Wong ${ }^{1,2,4} \cdot$ Arpan R. Mehta $^{1,2,4,6}$ - Rachel Dakin $^{1,2}$. \\ Siddharthan Chandran ${ }^{1,2,4,6}$. Judith Newton ${ }^{1,2} \cdot$ Alan Carson $^{1} \cdot$ Sharon Abrahams ${ }^{4,5}$. Suvankar Pal ${ }^{1,2,4}$
}

Received: 12 June 2020 / Revised: 27 August 2020 / Accepted: 29 August 2020 / Published online: 10 September 2020

(c) The Author(s) 2020

\begin{abstract}
Background Up to 50\% of people with amyotrophic lateral sclerosis (ALS) experience cognitive dysfunction, whilst depression and anxiety are reported in up to $44 \%$ and $33 \%$, respectively. These symptoms impact on quality of life, and are associated with a poorer prognosis. Historically, outcomes in clinical trials have focused on the effect of candidate drugs on physical functioning.

Methods We reviewed the past 25 years of clinical trials of investigative medicinal products in people with ALS, since the licensing of riluzole, and extracted data on frequency and type of assessment for neuropsychiatric symptoms and cognitive impairment. Trial registry databases, including WHO International Trials Registry, European Clinical Trials Register, clinicaltrials.gov, and PubMed, were systematically searched for Phase II, III or IV trials registered, completed or published between 01/01/1994 and 31/10/2019. No language restrictions were applied. Outcome measures, exclusion criteria and assessment tool used were extracted.

Results 216 trials, investigating 26,326 people with ALS, were reviewed. 35\% assessed neuropsychiatric symptoms, and $22 \%$ assessed cognition, as Exclusion Criteria or Outcome Measures. 3\% $(n=6)$ of trials assessed neuropsychiatric symptoms as a Secondary Outcome Measure, and 4\% $(n=8)$ assessed cognition as Outcome Measures; only one trial included assessments for both cognition and neuropsychiatric symptoms as Outcome Measures. Three ALS-specific assessments were used in six trials.

Conclusions Trials for people with ALS have neglected the importance of neuropsychiatric symptoms and cognitive impairment. Evaluation of these extra-motor features is essential to understanding the impact of candidate drugs on all symptoms of ALS.

PROPSERO registration CRD42020175612.
\end{abstract}

Keywords Amyotrophic lateral sclerosis $\cdot$ Motor neuron disease $\cdot$ Neuropsychiatric $\cdot$ Cognition $\cdot$ Clinical trials

\section{Introduction}

Electronic supplementary material The online version of this article (https://doi.org/10.1007/s00415-020-10203-z) contains supplementary material, which is available to authorized users.

Suvankar Pal

Suvankar.Pal@ed.ac.uk

1 Centre for Clinical Brain Sciences, The University of Edinburgh, Edinburgh, Scotland

2 Anne Rowling Regenerative Neurology Clinic, 49 Little France Crescent, EH16 4SB, Edinburgh, UK

3 The School of Medicine and Veterinary Medicine, The University of Edinburgh, Edinburgh, Scotland
Amyotrophic lateral sclerosis (ALS) has been traditionally characterised as a disease of the motor system [1]; however, extra-motor symptoms, including neuropsychiatric

4 Euan MacDonald Centre for MND Research, The University of Edinburgh, Edinburgh, Scotland

5 Human Cognitive Neurosciences, Psychology, School of Philosophy, Psychology and Language Sciences, The University of Edinburgh, Edinburgh, Scotland

6 UK Dementia Research Institute, The University of Edinburgh, Edinburgh, Scotland 
and cognitive symptoms, are now becoming more widely acknowledged as prevalent [2] and debilitating [3] features of this condition, and are predictive of disability [4].

Findings from a recent population-based study in Scotland reported a prevalence of neuropsychiatric disorders of $19.7 \%$ in people with ALS, $70 \%$ of which were mood disorders and $31.67 \%$ neurotic disorders (inclusive of anxiety, stress-related and somatoform disorders) [5].

The prevalence of these disorders in people with ALS is higher than that in the general population, $6.9 \%$ of whom meet thresholds for a depressive disorder and $14 \%$ an anxiety disorder [6,7]. These differences remain when focusing on a group more representative of the general individual with ALS, the older adult population [8].

Cognitive impairment is an additional extra-motor feature of ALS that is highly prevalent, with some form of cognitive or behavioural symptoms experienced by $30-50 \%$ of people with ALS [9]. 15\% of people with ALS meet diagnostic criteria for frontotemporal dementia (FTD) [10, 11]. Cognitive impairment in people with ALS is characterised by executive dysfunction, impairments in language and social cognition [12-14], whilst apathy is the most pronounced behavioural change [15].

Individuals with chronic physical illness and comorbid depression or anxiety often experience a higher level of somatic symptom burden that can impair functioning [16]. Symptoms of depression, anxiety and apathy reduce quality of life (QoL) for people with ALS [17, 18]. Lower psychological well-being generally has been identified as predictive of disability and shorter survival in people with ALS [4]. Presence of concomitant neuropsychiatric conditions and cognitive impairment predicts greater carer distress [19-21].

Despite this, neuropsychiatric symptoms are often underrecognised in clinical care. Assessments are often performed using tools which have not been adapted for people with physical disability or communication difficulties. Assessments may also not be specifically addressing the cognitive domains impaired in people with ALS, or providing disease-specific thresholds for impairment. Scores may be significantly impacted by the overlap of somatic features of neuropsychiatric conditions and those attributable to the progression of ALS. In a group that is predominantly affected by motor impairment, speech and respiratory difficulties, lengthy administration time can also reduce the suitability of an tool.

\section{Assessment in clinical trials}

The only globally licensed disease modifying therapy, riluzole [22], was introduced for use in people with ALS in the 1990s, following modest, but statistically significant prolongation of survival by two to three months [23-25]. Edaravone (Radicava) and masitinib have both emerged as promising treatments following positive trials in highly stratified cohorts [26], but neither have been licensed globally, owing to concerns around trial design and conduct. All of these current disease modifying therapies are intended to target the motor symptoms of ALS. To this end, research is underway to improve our understanding of the molecular mechanisms underlying ALS. This may in turn reveal potential important therapeutic targets, including those that modulate cognition [27, 28]. Cognitive assessments have been included in some studies investigating the effects of rilzuole as a disease modifying therapy in various other neurodegenerative conditions [29]. To our knowledge, the impact of riluzole on cognition in people with ALS has not been investigated in initial licensing trials.

There is an urgent need for more effective treatment options in ALS. Whilst survival and functioning remain the gold standard outcome measures used in clinical trials, incorporation of measures of neuropsychiatric and cognitive function enable more holistic assessment of the impact of drugs. Awareness of how a candidate drug may affect extramotor features is clinically revelant in disease management and quality of life.

Including individuals with neuropsychiatric and cognitive impairments, and using assessments to evaluate changes in these areas as outcome measures will enable the trial teams to evaluate the impact of the candidate drugs on people with extra-motor features of ALS.

Candidate drugs may have a selective effect on neuropsychiatric or cognitive symptoms; therefore, measurement of these areas is pertinent to investigate the impact of an investigative medicinal product on both motor and extra-motor symptoms in ALS. The potential impact of candidate drugs is of therapeutic relevance, even if not the primary intended effect, considering the possible affect on quality of life and disease mangement of ALS.

Indeed, the 2019 revision of Airlie House consensus guidelines for design and implementation of ALS clinical trials [30] recommends that "Investigators may include assessments of cognitive or behavioral function as primary or secondary outcome measures". Despite evolving guidance, and significant progess in establishing cognitive assessments within clinical care [31], we hypothesised that neuropsychiatric and cognitive symptoms have been underevaluated in clinical trials and that when assessed using standardised tools, these tools are not specifically designed for people with ALS, which may affect their suitability for use in this population.

We aimed to systematically review 25 years of clinical trials in ALS, since the licensing of riluzole, to identify if neuropsychiatric symptoms and cognitive impairment were evaluated. If they were evaluated, we assessed if this was as 
an exclusion criteria or outcome measure and describe the tools used.

\section{Methods}

We completed a systematic, unbiased, search of trial registries including clinicaltrials.gov, World Health Organisation's (WHO) International Clinical Trials Registry Platform (ICTRP), European Union Clinical Trials Register (EduraCT) and PubMed on 18/11/2019 for Clinical Trials of an Investigational Medicinal Product (CTIMPs).

Using the search terms "amyotrophic lateral sclerosis" or "motor neuron* disease" we searched clinicaltrials.gov for interventional trials of investigative medicinal products. We searched European Union Clinical Trials Register (EduraCT) and WHO International Clinical Trials Registry Platform (ICTRP) for trials of "amyotrophic lateral sclerosis" with the filters "Phase II", "Phase III" and "Phase IV" applied. Using the advanced search feature we filtered PubMed with ["amyotrophic lateral sclerosis"(MeSH Terms) OR "motor neuron* disease"(MeSH Terms)]. We then applied the 'Clinical Trial' filter for Article Type, Human trials only and Publication Date within the criteria defined above.

Phase II, III or IV trials assessing potential disease modifying therapies in subjects with amyotrophic lateral sclerosis that were registered, completed or published between $01 / 01 / 1994$ to $31 / 10 / 2019$ were included. No language restrictions were applied. Extension trials, post-hoc analysis papers and trials focused on symptom management were excluded.

\section{Data extraction}

The following details of selected trials were extracted: "Investigative Medicinal Product (IMP) Assessed", "Number of Participants", "Date of Commencement", "Primary Outcome Measure(s)" and "Secondary Outcome Measure(s)".

Assessment of neuropsychiatric conditions or cognitive symptoms within each trial was categorised as follows: "Exclusion Criteria", "Primary Outcome Measure", "Secondary Outcome Measure", "No Data Available for Trial" or "Not Assessed". We also noted the assessment tool included, if documented, and a brief summary of the trial's stipulations regarding neuropsychiatric conditions or cognitive symptoms. We also evaluated the use of Quality of Life measures within the trials. We investigated the number of clinical trials that recruited people with fronto-temporal dementia (FTD).

We documented the tools used and described the characteristics of tools used to evaluate neuropsychiatric or cognitive symptoms in trials identified in this systematic review.
The areas assessed, features of administration and availability of disease-specific scores were recorded.

\section{Results}

\section{Overview}

A total of 1,312 records were identified (see PRISMA diagram in Fig. 1 for details). 296 duplicates were removed and a further 800 results were removed due to unsuitability (defined by inclusion criteria with full overview in Fig. 1); non-CTIMP and non-ALS subjects were the primary reasons for excluding search results. This resulted in 216 clinical trials of investigative medicinal products. 216 trials, proposed to include a total of 26,326 participants with ALS, were included in the final review.

Only one trial, the Therapy in Amyotrophic Lateral Sclerosis (TAME) trial evaluating memantine (Barohn et al., currently recruiting, Trial ID: NCT02118727), assessed both neuropsychiatric symptoms and cognitive impairment as Secondary Outcome Measures. A full list of the 13 trials assessing neuropsychiatric symptoms and cognitive impairment as primary or secondary outcome measures, the current status and results' availability is shown in Table 1.

Four trials had results available. In the trial of memantine (NCT00353665) the use of Hamilton depression scale as a planned secondary outcome measure was noted in the trial record on clinicaltrials.gov; however, there was no discussion of use or results of this outcome in the final report of the trial findings [32]. In a trial evaluating lithium carbonate (EudraCT 2008-006,891-31), depression worsened and anxiety increased over time in participants, but there was no significant difference between study groups [33].

A trial of omigapil (NCT00072709) reported no change in neurocognitive evaluations, utilising the Addenbrooke's Cognitive Examination (ACE) [34]. The triumeq trial (NCT02868580) assessed suicidal ideation as a secondary outcome measure using the Columbia Suicide Severity Rating Scale (C-SSRS). Only two participants (5\% of total trial participants) reported suicidal ideation and this was deemed unrelated to triumeq [35].

\section{Neuropsychiatric symptoms}

$35 \%(n=76 / 216)$ of the total 216 trials included in this review assessed neuropsychiatric symptoms. Of these 76 trials, 92\% ( $n=70 / 76)$ assessments were used as an Exclusion Criteria, 3\% $(n=2 / 76)$ as a Secondary Outcome Measure and $5 \%(n=4 / 76)$ defined neuropsychiatric symptoms 


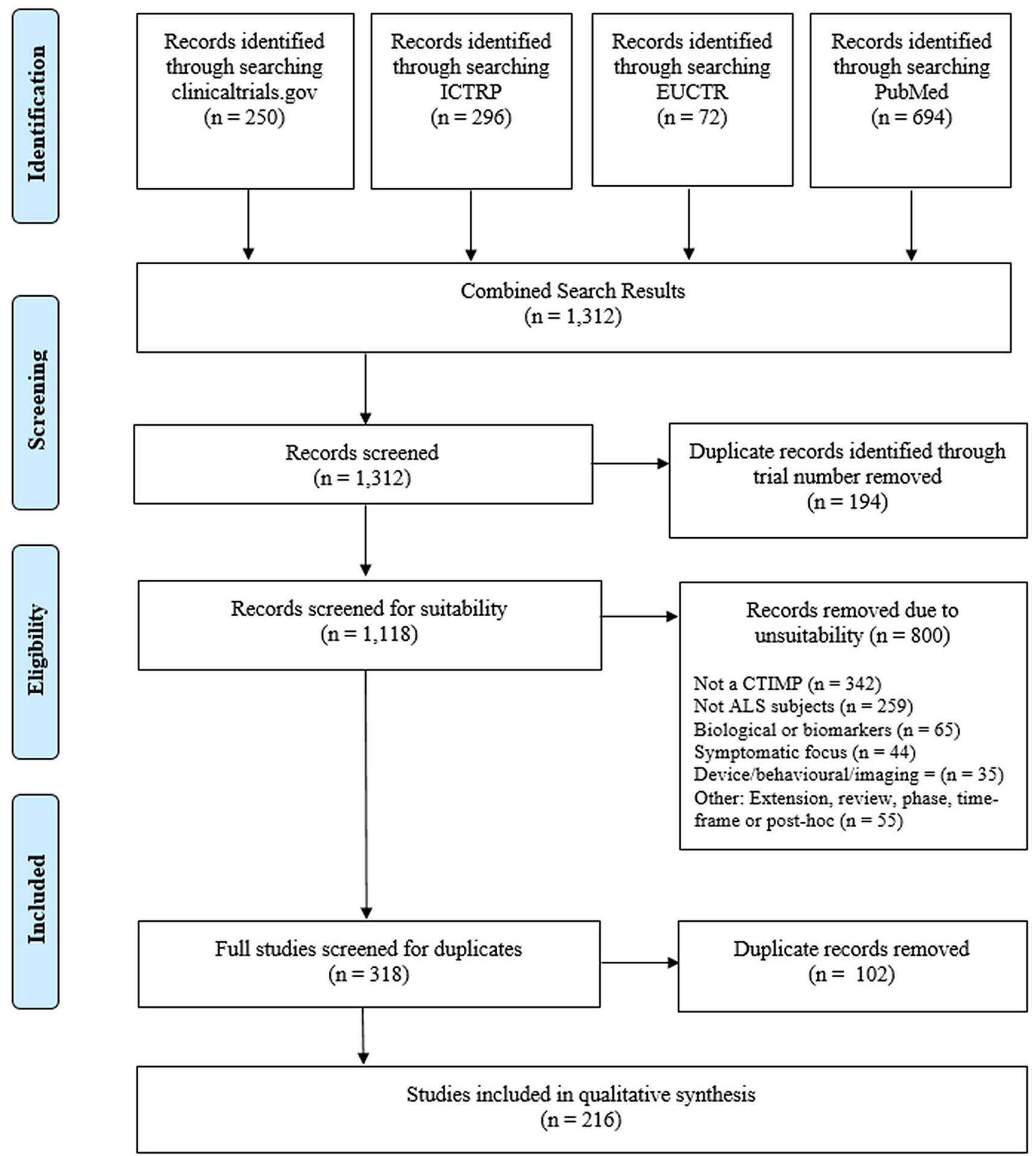

Fig. 1 PRISMA Diagram for Record Selection. From Moher D, et al [71]. For more information, visit https://www.prisma-statement.org

as both a Secondary Outcome Measure and an Exclusion Criterion.
$29 \%(n=22 / 76)$ of the 76 trials that reported assessing neuropsychiatric symptoms utilized investigator clinical judgement, $32 \%(n=24 / 76)$ clinical history or medical records and $11 \%(n=8 / 76)$ specified a standardized assessment tool. 


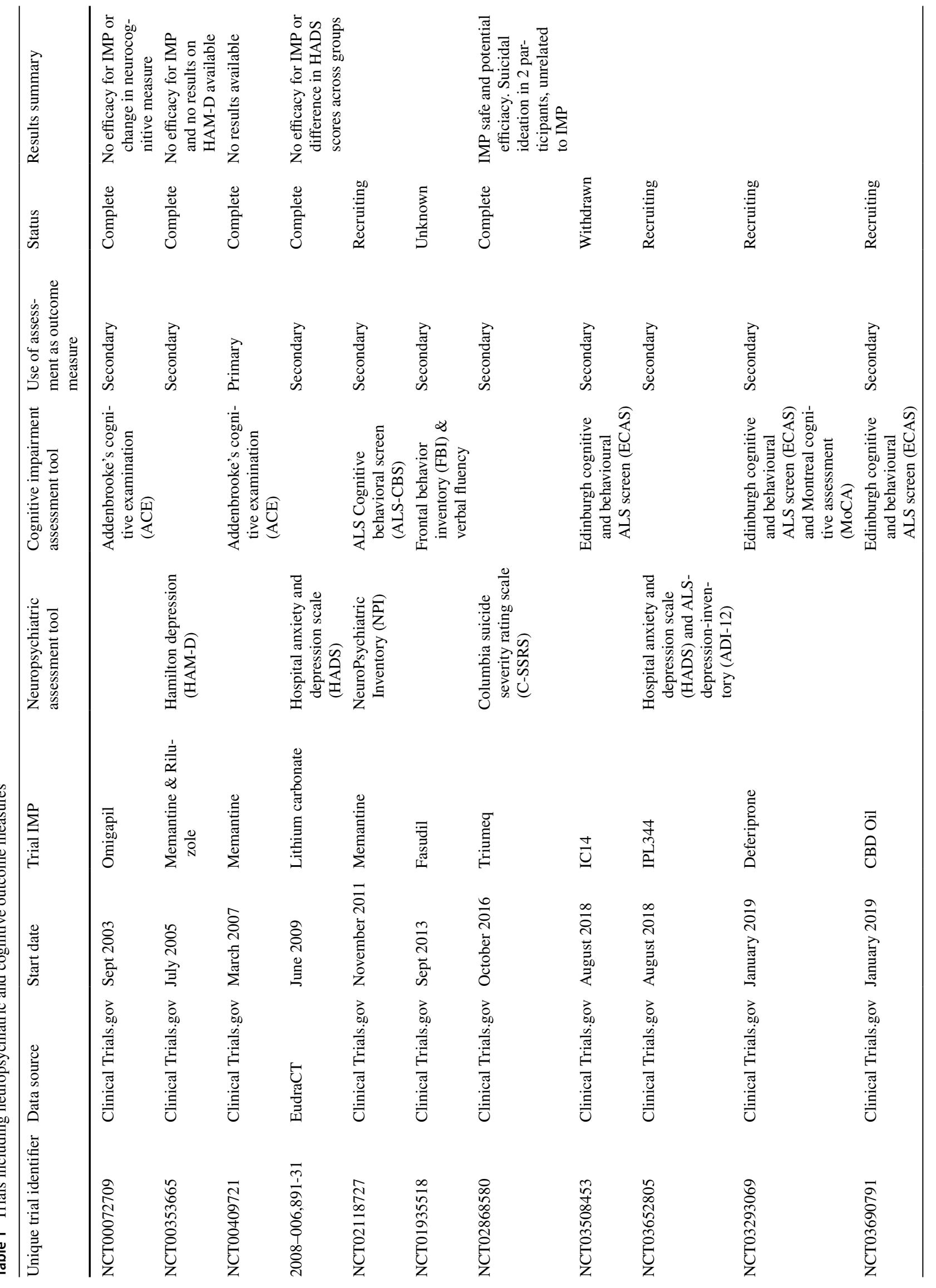




\section{Cognitive impairment}

$21 \%$ ( $n=46 / 216)$ of the 216 trials included assessed cognitive functioning. Of these 46 trials assessing cognitive functioning, 83\% $(n=38 / 46)$ assessments were used as an Exclusion Criteria, $4 \%(n=2 / 46)$ as a Primary Outcome Measure and $13 \%(n=6 / 46)$ as a Secondary Outcome Measure.

Of these 46 trials which reported assessing cognitive impairment and provided data on the method of assessment, 23\% ( $n=11)$ utilized investigator clinical judgement, 9\% $(n=4)$ clinical history or medical records and $26 \%(n=12)$ specified a standardized assessment tool.

The Edinburgh Cognitive and Behavioural ALS Screen (ECAS) was the only assessment tool used as both a Primary and Secondary Outcome Measure to assess cognitive impairment in people with ALS.

A comorbid diagnosis of dementia was an Exclusion Criteria in $32 \%(n=69)$ of the 216 trials reviewed. Subjects with dementia were explicitly referenced as able to participate in just $1 \%$ of trials $(n=3) .67 \%(n=144)$ did not provide data on whether they accepted participants with a dementia diagnosis.

Quality of life measures were utilized as Primary and Secondary Outcome Measures in 1\% $(n=3)$ and 27\% $(n=59)$, respectively, of 216 trials reviewed. Table 2 summarises quality of life measures used and considers their content as some measures include limited assessments of mood and self-reported psychological health and functioning.

\section{Characteristics of assessment tools identified}

The only tool specifically designed and validated for neuropsychiatric assessment in people with ALS, the ALS Depression Inventory (ADI-12) [36], was used in one trial. This tool is validated to screen for depressive symptoms in people with ALS, with a sensitivity of $100 \%$ and specificity of $82 \%$, meaning all people with a major depressive disorder were identified [36]. However, this tool focuses only on the evaluation of depression and does not account for the range of neuropsychiatric symptoms which may affect people with ALS.

The other tools used in the trials included in this review are Beck's Depression Inventory (BDI) [37], Hamilton Depression Inventory (HAM-D) [38], Columbia Suicide Severity Score (C-SSRS) [39], Hosptial Anxiety and Depression Scale (HADS) [40] and the Neuropsychiatric Inventory Questionnaire (NPI-Q) [41]. The BDI and HAM-D are extensively validated [42,43], well-established measures of depressive symptoms. However, their reliance on somatic features of depression mean scores may be confounded by physical decline and no ALS-specific impairment thresholds are available. The HADS is designed to reduce the focus on 
Table 2 Quality of life assessment tools and areas assessed

\begin{tabular}{|c|c|c|c|c|}
\hline Assessment name & $\begin{array}{l}\text { Total } \\
\text { number of } \\
\text { items }\end{array}$ & $\begin{array}{l}\text { Number } \\
\text { of trials } \\
\text { utilised }\end{array}$ & Domains addressed & Mood items \\
\hline $\begin{array}{l}\text { Amyotrophic lateral sclerosis } \\
\text { assessment questionnaire-40 Item } \\
\text { (ALSAQ-40) }\end{array}$ & 40 & 14 & $\begin{array}{l}\text { Hopelessness, depression and emo- } \\
\text { tional reactivity }\end{array}$ & $\begin{array}{l}\text { Ten items with 5-point Likert scale for } \\
\text { frequency of mood symptoms }\end{array}$ \\
\hline $\begin{array}{l}\text { Amyotrophic lateral sclerosis } \\
\text { assessment questionnaire-5 Item } \\
\text { (ALSAQ-5) }\end{array}$ & 5 & 6 & Hopelessness & $\begin{array}{l}\text { One item with 5-point Likert scale on } \\
\text { frequency of hopelessness }\end{array}$ \\
\hline $\begin{array}{l}\text { ALS specific quality of life } \\
\text { (ALSQOL-R) }\end{array}$ & 50 & 6 & Depression and anxiety & $\begin{array}{l}\text { Ten-point Likert rating scales for } \\
\text { level of agreement or frequency of } \\
\text { experiences }\end{array}$ \\
\hline $\begin{array}{l}\text { EuroQol } 5 \text { domain assessment (EQ- } \\
\text { 5D-5L) }\end{array}$ & 5 & 4 & $\begin{array}{l}\text { Health perception and functional } \\
\text { impact }\end{array}$ & $\begin{array}{l}\text { Five-point Likert rating scale for } \\
\text { severity of anxiety/depression } \\
\text { combined }\end{array}$ \\
\hline $\begin{array}{l}\text { Edmonton symptom assessment } \\
\text { system (ESAS) }\end{array}$ & 10 & 1 & $\begin{array}{l}\text { Pain, depression, anxious and gen- } \\
\text { eral wellbeing }\end{array}$ & $\begin{array}{l}\text { 10-point Likert rating scale for depres- } \\
\text { sion and anxiety }\end{array}$ \\
\hline McGill quality of life-revised & 14 & 7 & $\begin{array}{l}\text { Depression, anxiety, mood and } \\
\text { hopelessness }\end{array}$ & $\begin{array}{l}\text { 10-point Likert scale for severity of } \\
\text { mood symptoms in previous } 48 \mathrm{~h}\end{array}$ \\
\hline $\begin{array}{l}\text { Schedule for the evaluation of indi- } \\
\text { vidual quality of life questionnaire } \\
\text { (SEIQoL) }\end{array}$ & 3 & 1 & $\begin{array}{l}\text { Self-reported areas of concern and } \\
\text { effect on function }\end{array}$ & $\begin{array}{l}\text { Identify five most important areas in } \\
\text { their life and rate importance }\end{array}$ \\
\hline $\begin{array}{l}\text { Short form patient questionnaire - } 12 \\
\text { item (SF-12) }\end{array}$ & 12 & 3 & Emotional problems & $\begin{array}{l}\text { Two items identifying the extent to } \\
\text { which emotional problems affected } \\
\text { activities }\end{array}$ \\
\hline $\begin{array}{l}\text { Short form patient questionnaire - } 36 \\
\text { item (SF-36) }\end{array}$ & 36 & 6 & Low mood, lack of energy, anxiety & $\begin{array}{l}\text { Four items identifying the extent to } \\
\text { which emotional problems affected } \\
\text { activities }\end{array}$ \\
\hline $\begin{array}{l}\text { Sickness impact profile - ALS Items } \\
\text { (SIP/ALS-19) }\end{array}$ & 19 & 1 & $\begin{array}{l}\text { ALS-adapted SIP Focus on activi- } \\
\text { ties of daily living, self-care and } \\
\text { activities }\end{array}$ & $\begin{array}{l}\text { No items specifically focused on } \\
\text { mood, } 1 \text { item on social interaction }\end{array}$ \\
\hline $\begin{array}{l}\text { Visual analogue scale (VAS-3 } \\
\text { health status questions) }\end{array}$ & 3 & 1 & $\begin{array}{l}\text { General, physical and mental health } \\
\text { self-rating }\end{array}$ & $0-100$ scale for overall mental health \\
\hline $\begin{array}{l}\text { Visual analogue scale and patient's } \\
\text { global impression of change }\end{array}$ & 2 & 1 & Pain and self-perception of health & $\begin{array}{l}\text { 7-point and 10-point Likert rating } \\
\text { scales for change in emotion and } \\
\text { overall quality of life }\end{array}$ \\
\hline
\end{tabular}

somatic symptoms and ALS-specific impairment thresholds have been proposed [44].

The C-SSRS is considered a useful tool to structure discussions of suicidal ideation and intent [45]. However, the C-SSRS can be lengthy to administer, insufficient to cover the full spectrum of suicidal ideation [46] and responses to questions of end-of-life planning may be influenced by the presence of a terminal diagnosis. The NPI-Q is a validated informant-based questionnaire to evaluate the presence and severity of 12 neuropsychiatric domains [47]. The ability of the tool to discriminate effectively between different disorders has been questioned [48].

Of the eight trials that did assess cognitive and behaviour change as an outcome measure, six used tools where scoring was unaffected by physical disability or communication impairment and were specifically designed, and validated, to identify domains impaired in people with ALS. One trial used the ALS Cognitive Behavioral Screen (ALS-CBS) [49] and five trials used the Edinburgh Cognitive and Behavioural ALS Screen (ECAS) [50].

The ALS-CBS is a brief assessment of executive functions while the ECAS assesses a wider profile of cognitive and behavioural impairment in ALS including executive and language functions, fluency and social cognition. Both are designed to be completed by either written or spoken responses to be suitable for ALS patients with differing functional ability. Additionally, ECAS scoring is also corrected for differences in motor speed during both speech and writing tasks, to accommodate for a range in disability severity.

Additionally, the Montreal Cognitive Assessment Scale (MoCA) [51], Addenbrooke's Cognitive Examination (ACEIII) [52] and Mini Mental State Examination (MMSE) were used to evaluate cognition in the trials reviewed. Although widely validated for use in neurological conditions, particularly dementia, these tools were not specifically designed to assess the cognitive profile of people with ALS. As a result, 
no ALS-adapted thresholds for impairment were available and scoring on the tools was potentially impacted by motor decline experienced in ALS.

Verbal fluency is a commonly found deficit in ALS and is included as a sub-test on other cognitive assessments identified in this review and as a standalone test of cognition in one trial. However, it was not clear from the trial record if motor speed was controlled for in the assessment which can affect interpretation of the scores [12].

The Frontal Behavior Inventory (FBI) [53] and the behavioural interview of the ECAS and ALS-CBS were utilised to screen for behavioural symptoms which may be indicative of fronto-temporal dementia.

An additional assessment tool utilised by one trial, to exclude individuals with an intellectual disability, is the Weschler Adult Intelligence Scale (WAIS) [54]. As the WAIS was intend to screen for lower intelligence quotients rather than specific cognitive impairments we have not included this tool in Table 3 which focuses specifically on tools used to assess neuropsychiatric symptoms and cognitive impairment.

Table 3 Characteristics of tools used to evaluate cognition and neuropsychiatric symptoms

\begin{tabular}{|c|c|c|c|c|c|c|}
\hline & $\begin{array}{l}\text { Area assessed in } \\
\text { trials }\end{array}$ & Domains & $\begin{array}{l}\text { Designed for, or } \\
\text { adapted for ALS with } \\
\text { abnormality cut-offs }\end{array}$ & $\begin{array}{l}\text { Administra- } \\
\text { tion time } \\
(\min )\end{array}$ & Total score & References \\
\hline $\begin{array}{l}\text { Beck's depression } \\
\text { inventory }\end{array}$ & Depression & Depression & - & $5-10$ & 63 & {$[37]$} \\
\hline $\begin{array}{l}\text { Columbia suicide } \\
\text { severity score }\end{array}$ & Suicidality & Suicidality & - & $5-30$ & $\begin{array}{l}\text { Binary outcome of } 10 \\
\text { categories }\end{array}$ & [39] \\
\hline $\begin{array}{l}\text { Hamilton depression } \\
\text { scale }\end{array}$ & Depression & Depression & - & $20-30$ & 52 & {$[38]$} \\
\hline $\begin{array}{l}\text { Hospital anxiety and } \\
\text { depression scale }\end{array}$ & $\begin{array}{l}\text { Anxiety and depres- } \\
\text { sion }\end{array}$ & $\begin{array}{l}\text { Anxiety and depres- } \\
\text { sion }\end{array}$ & + & $5-10$ & 21 per disorder & {$[40,44]$} \\
\hline $\begin{array}{l}\text { Neuropsychiatric } \\
\text { inventory question- } \\
\text { naire }\end{array}$ & Depression & $\begin{array}{l}\text { Neuropsychiatric } \\
\text { conditions }\end{array}$ & - & 5 & $\begin{array}{c}100 \text { for } 10 \text {-item \& } \\
144 \text { for } 12 \text {-item }\end{array}$ & {$[41,47]$} \\
\hline $\begin{array}{l}\text { Amyotrophic lateral } \\
\text { sclerosis depression } \\
\text { inventory }\end{array}$ & Depression & Depression & + & 5 & 48 & {$[36,66]$} \\
\hline $\begin{array}{l}\text { Amyotrophic lateral } \\
\text { sclerosis cognitive } \\
\text { behavioural screen }\end{array}$ & $\begin{array}{l}\text { Cognition and behav- } \\
\text { iour }\end{array}$ & $\begin{array}{l}\text { Executive functioning } \\
\text { and behaviour }\end{array}$ & + & $5-10$ & $\begin{array}{l}20 \text { for cognitive } \\
\text { section }\end{array}$ & {$[49,61]$} \\
\hline $\begin{array}{l}\text { Addenbrooke's cogni- } \\
\text { tive examination }\end{array}$ & Cognition & $\begin{array}{l}\text { Attention, memory, } \\
\text { verbal fluency, } \\
\text { language and } \\
\text { visuospatial }\end{array}$ & - & $15+$ & 100 & {$[67]$} \\
\hline $\begin{array}{l}\text { Montreal cognitive } \\
\text { assessment }\end{array}$ & Cognition & General cognition & - & $10-15$ & 30 & {$[51,68]$} \\
\hline $\begin{array}{l}\text { Edinburgh cognitive } \\
\text { and behavioural } \\
\text { assessment screen }\end{array}$ & $\begin{array}{l}\text { Cognition and behav- } \\
\text { iour }\end{array}$ & $\begin{array}{l}\text { Executive function- } \\
\text { ing, language, } \\
\text { fluency, memory, } \\
\text { visuospatial, social } \\
\text { cognition, verbal } \\
\text { fluency index and } \\
\text { behaviour }\end{array}$ & + & $15-25$ & $\begin{array}{l}136 \text { for cognitive } \\
\text { section }\end{array}$ & {$[50]$} \\
\hline $\begin{array}{l}\text { Frontal behavioural } \\
\text { inventory }\end{array}$ & Behaviour & $\begin{array}{l}\text { Behaviours character- } \\
\text { istic of FTD }\end{array}$ & - & $15-30$ & $\begin{array}{l}\text { Severity rating } 0-3 \\
\text { on } 24 \text { items }\end{array}$ & {$[53,69]$} \\
\hline Verbal fluency & Cognition & Language & + & $<5$ & N/A & {$[12,53]$} \\
\hline $\begin{array}{l}\text { Mini mental state } \\
\text { examination }\end{array}$ & Cognition & General cognition & - & $<5$ & 30 & {$[70]$} \\
\hline
\end{tabular}

+ Test designed or adapted for ALS and ALS-specific impairment thresholds are available

-Test not designed/adapted for ALS and no ALS-specific impairment thresholds currently available

NB Time to administer is indicated as a guide only. This will vary depending upon the respondent's functional ability, presence of a communication impairment and use of assistive devices and the researcher's experience in administering the instrument 


\section{Discussion}

This review of 216 clinical trials from the last 25 years of ALS research highlights that the assessment of neuropsychiatric and cognitive symptoms has been frequently neglected. Only one trial assessed the impact of the candidate drug on both neuropsychiatric symptoms and cognitive impairment. This is despite overwhelming evidence that these extramotor features are prevalent across, and impactful upon, people with ALS $[5,9,20]$.

Whilst the impact on physical functioning and survival justifiably remain the primary objectives for clinical trials of ALS, the importance of additional assessments for neuropsychiatric and cognitive functioning needs to be addressed. This will enable future trial design to align with the 2019 revision of Airlie House consensus guidelines, recommendations for the design and implementation of clinical trials in ALS [30].

As the only globally licensed treatment for ALS, riluzole use is sometimes an exclusion criteria, or a minimisation criteria at point of randomisation, in many ALS trials. The effect of riluzole on cognition in people with ALS is not yet established, with study results reporting variable impact [56, 57]. Frequent inclusion in trials in other neurological conditions, and conflicting findings, provides further justification for the inclusion of cognitive measures to evaluate how established medications such as riluzole, and exploratory study drugs, impact upon people with ALS.

\section{Assessment of neuropsychiatric symptoms in clinical trials}

Despite research indicating the presence of neuropsychiatric symptoms and comorbidities as pervasive $[3,55]$ and pernicious [56] in people with ALS, the impact of candidate drugs on neuropsychiatric functioning is underevaluated. Of the 216 trials included in this review, only eight reported using a formal neuropsychiatric assessment tool. Accuracy of evaluation is additionally hindered by the limited availability of tools specifically designed and validated for neuropsychiatric evaluation of the ALS population. To evaluate the impact of candidate drugs on neuropsychiatric domains potentially affected in ALS, without significant confounding of physical disability, a greater understanding of the validity of these measures in ALS trials is needed.

\section{Assessment of cognition in clinical trials}

The past 15 years of research has highlighted the ubiquity of cognitive and behavioural impairment in people with ALS, [50,57]. Whilst the assessment of these changes has become widely accepted in clinical care for people with ALS [58], clinical trials are lagging behind, with only $21 \%$ of the 216 trials reviewed in this study assessing cognition.

The inclusion of cognitive assessment in clinical trial design as an additional outcome measure is progressing slightly. In the previous decade of research, 2010-2020 inclusive, $7 \%(n=6)$ of 86 trials registered, commenced or published within this time frame assessed cognition as an outcome measure. In comparison, of 101 trials from the decade prior, $2000-2010,2 \%(n=2)$ assessed cognition as an outcome measure.

Cognitive assessment in trial design is also increasing in accuracy, in part due to the availability of ALS-specific tools validated specifically to assess the domains impaired in this cohort $[49,59]$, particularly the ALS Cognitive Behavioral Screen (ALS-CBS) and Edinburgh Cognitive and Behavioural ALS Screen (ECAS) in the trials reviewed here. Cognitive assessments used previously may not be suitable for individuals with physical disabilities, due to an over-reliance on motor tasks, and limited focus on cognitive domains impaired in people with ALS.

Our review focused on the inclusion of cognitive functioning assessment in trial design; however, assessing evolution in in cognitive functioning during disease trajectory may also be of interest in future trial design. Longitudinal cognitive assessments were evaluated as an outcome measure in the ALS Multicenter Cohort Study of Oxidative Stress (ALS COSMOS [60]). Baseline data in this study of 247 participants evaluated with the ALS-CBS indicated that cognitive and behavioural impairments were common, $6.5 \%$ scoring below cut-offs for frontotemporal dementia [49], 54.2\% scoring consistent with mild cognitive impairment and behavioural subscores outwith the normal range in $30.6 \%$ of responders [61]. Analysis of longitudinal data did not detect cognitive decline over a 12-month period but did detect an increase in behavioural changes, notably disinhibition, while initial behavioural impairment predicted attrition [62]. Other studies have demonstrated increasing prevalence of cognitive and behavioural impairment in later disease stages [63, 64].

Non-interventional studies which have assessed change in cognition over time have shown mixed results $[64,65]$. Attrition of individuals with cognitive and/or behavioural impairments from longituinal repeated assessments may also bias the sample towards individuals with slower disease progression and more stable cognitive functions.

Only one trial in this review, the Omigapil trial (NCT00072709), reported data on cognitive otucomes. No change in neurocognitive secondary outcome measure was reported, with the Addenbrooke's Cognitve Examination (ACE) [34]. Understanding of cognitive change across the disease course is of prime importance for the interpretation of cognitive data in clinical trials. 


\section{Impact on generalisability of trial findings}

A diagnosis, historical or current, of symptoms of a neuropsychiatric disorder was still explicitly identified as an exclusion criterion for the majority of trials included in this study.

Cognitive impairment was also often included as an exclusion criterion, with thresholds for impairment often subjective or not addressed. This could be due to researchers' concerns over capacity to consent, potential issues with trial adherence, compliance with assessments and following medication regimens.

Ultimately, results from studies with strict exclusion criteria, which reduce the sample representativeness of a heterogenous patient group, may not be generalisable to the whole ALS population. Furthermore, excluding individuals with neuropsychiatric conditions and cognitive impairment, unless when absolutely necessary, and neglecting to include these aspects as outcome measures, misses a vital opportunity to explore how candidate drugs may affect people with ALS across this diverse condition.

\section{Conclusion}

This study clearly demonstrates that the impact of candidate drugs on neuropsychiatric symptoms and cognition has been under-evaluated in clinical trials and that when these symptoms have been evaluated, the tools used may not be suitable for people with ALS.

Accurate identification of neuropsychiatric comorbidity and cognitive impairment is an essential requirement to improve our understanding of how candidate drugs impact the extra-motor features of ALS.

We recommend the evaluation of neuropsychiatric and cognitive symptoms as additional outcome measures in clinical trials of investigative medicinal products. Additionally, when evaluating these areas we recommend using tools which are designed to assess domains affected in ALS, with disease-specific impairment thresholds and those adapted to account for motor decline and communication difficulties.

Author contributions SP and EB contributed to the conception of the project. $\mathrm{EB}, \mathrm{EP}$, and $\mathrm{CW}$ carried out the data analysis. SP, EB, CW, ARM, SC, RD, JN, AC and SA drafted the manuscript. The manuscript was reviewed by all authors.

Funding The authors acknowledge funding from the Euan MacDonald Centre for MND Research. A.R.M. is a Lady Edith Wolfson Clinical Fellow and is jointly funded by the Medical Research Council (MRC) and the Motor Neurone Disease Association (MR/R001162/1). S.C. is supported by the UK Dementia Research Institute (DRI), which receives its funding from UK DRI Ltd, funded by the MRC, Alzheimer's Society and Alzheimer's Research UK.
Code availability Not applicable.

\section{Compliance with ethical standards}

Conflicts of interest Professor Carson is a paid editor at Journal of Neurology, Neurosurgery and Psychiatry, and gives independent testimony in Court on a range of neuropsychiatric topics.

Ethical standard The authors confirm that this article complies with ethical standards.

Availability of data and material Supplementary Material Document 1.

Open Access This article is licensed under a Creative Commons Attribution 4.0 International License, which permits use, sharing, adaptation, distribution and reproduction in any medium or format, as long as you give appropriate credit to the original author(s) and the source, provide a link to the Creative Commons licence, and indicate if changes were made. The images or other third party material in this article are included in the article's Creative Commons licence, unless indicated otherwise in a credit line to the material. If material is not included in the article's Creative Commons licence and your intended use is not permitted by statutory regulation or exceeds the permitted use, you will need to obtain permission directly from the copyright holder. To view a copy of this licence, visit http://creativecommons.org/licenses/by/4.0/.

\section{References}

1. Chio A et al (2009) Prognostic factors in ALS: a critical review. Amyotrophic Lateral Sclerosis 10(5-6):310-323

2. Wicks P et al (2007) Prevalence of depression in a 12-month consecutive sample of patients with ALS. Eur J Neurol 14(9):993-1001

3. Zucchi E, Ticozzi N, Mandrioli J (2019) Psychiatric symptoms in amyotrophic lateral sclerosis: beyond a motor neuron disorder. Front Neurosci 13:19-67

4. Johnston M et al (1999) Mood as a predictor of disability and survival in patients newly diagnosed with ALS/MND. Br J Health Psychol 4(2):127-136

5. McHutchison CA et al (2020) Relationship between neuropsychiatric disorders and cognitive and behavioural change in MND. J Neurol Neurosurg Psyc 91(3):245-253

6. Wittchen $\mathrm{H}-\mathrm{U}$ et al (2011) The size and burden of mental disorders and other disorders of the brain in Europe 2010. Eur Neuropsychopharmacol 21(9):655-679

7. Ohayon MM et al (1999) The prevalence of depressive disorders in the United Kingdom. Biol Psychiat 45(3):300-307

8. Gonçalves DC, Pachana NA, Byrne GJ (2011) Prevalence and correlates of generalized anxiety disorder among older adults in the Australian National Survey of Mental Health and Well-Being. J Affect Disord 132(1-2):223-230

9. Benbrika $\mathrm{S}$ et al (2019) Cognitive, emotional and psychological manifestations in amyotrophic lateral sclerosis at baseline and overtime: a review. Frontiers Neurosci 13:951

10. Goldstein LH, Abrahams S (2013) Changes in cognition and behaviour in amyotrophic lateral sclerosis: nature of impairment and implications for assessment. Lancet Neurol 12(4):368-380

11. Strong MJ et al (2017) Amyotrophic lateral sclerosis-frontotemporal spectrum disorder (ALS-FTSD): revised diagnostic criteria. Amyot Lateral Scle Front Degen 18(3-4):153-174 
12. Abrahams S et al (2000) Verbal fluency and executive dysfunction in amyotrophic lateral sclerosis (ALS). Neuropsychologia 38(6):734-747

13. Taylor LJ et al (2013) Is language impairment more common than executive dysfunction in amyotrophic lateral sclerosis? J Neurol Neurosurg Psychiatry 84(5):494-498

14. Girardi A, MacPherson SE, Abrahams S (2011) Deficits in emotional and social cognition in amyotrophic lateral sclerosis. Neuropsychology 25(1):53

15. Radakovic R et al (2016) Multidimensional apathy in ALS: validation of the Dimensional Apathy Scale. J Neurol Neurosurg Psychiatry 87(6):663-669

16. Katon W, Lin EH, Kroenke K (2007) The association of depression and anxiety with medical symptom burden in patients with chronic medical illness. Gen Hosp Psychiatry 29(2):147-155

17. Lou J-S et al (2003) Fatigue and depression are associated with poor quality of life in ALS. Neurology 60(1):122-123

18. Caga $J$ et al (2018) Apathy and its impact on patient outcome in amyotrophic lateral sclerosis. J Neurol 265(1):187-193

19. Watermeyer TJ et al (2015) Impact of disease, cognitive and behavioural factors on caregiver outcome in amyotrophic lateral sclerosis. Amyot Lateral Scler Frontotemp Degen 16(5-6):316-323

20. Bock $M$ et al (2016) Cognitive-behavioral changes in amyotrophic lateral sclerosis: screening prevalence and impact on patients and caregivers. Amyot Lateral Scler Frontotemp Degen 17(5-6):366-373

21. Goldstein L et al (2006) Predictors of psychological distress in carers of people with amyotrophic lateral sclerosis: a longitudinal study. Psychol Med 36(6):865-875

22. Miller RG (2012) JD Mitchell, DH Moore, Riluzole for amyotrophic lateral sclerosis (ALS)/motor neuron disease (MND). Cochrane Database Syst Rev 3:6

23. Bensimon $\mathrm{G}$ et al (1994) A controlled trial of riluzole in amyotrophic lateral sclerosis. N Engl J Med 330(9):585-591

24. Group II RS (1996) Dose-ranging study of riluzole in amyotrophic lateral sclerosis. Lancet 347(913):1425-1431

25. Yanagisawa $\mathrm{N}$ et al (1997) Efficacy and safety of riluzole in patients with amyotrophic lateral sclerosis: double-blind placebocontrolled study in Japan. Igakuno Ayumi 182:851-866

26. Bhandari R, Kuhad A (2018) Edaravone: a new hope for deadly amyotrophic lateral sclerosis. Drugs Today 54(6):349-360

27. Gregory JM et al (2019) Neuronal clusterin expression is associated with cognitive protection in amyotrophic lateral sclerosis. Neuropathol Appl Neurobiol 3:8

28. Gregory JM et al (2020) Executive, language and fluency dysfunction are markers of localised TDP-43 cerebral pathology in nondemented ALS. J Neurol Neurosurg Psychiatry 91(2):149-157

29. Pillinger $\mathrm{T}$ et al (2019) Altered glutamatergic response and functional connectivity in treatment resistant schizophrenia: the effect of riluzole and therapeutic implications. Psychopharmacology 236(7):1985-1997

30. Van Den Berg LH et al (2019) Revised Airlie House consensus guidelines for design and implementation of ALS clinical trials. Neurology 92(14):e1610-e1623

31. National CGCU (2016) Motor Neurone Disease. Assess Managt $4: 9$

32. De Carvalho $\mathrm{M}$ et al (2010) A randomized, placebo-controlled trial of memantine for functional disability in amyotrophic lateral sclerosis. Amyot Lateral Scler Frontotemp Degen 11(5):456-460

33. Group, U.-L.S. (2013) Lithium in patients with amyotrophic lateral sclerosis (LiCALS): a phase 3 multicentre, randomised, double-blind, placebo-controlled trial. The Lancet Neurol 12(4):339-345

34. Miller R et al (2007) Phase II/III randomized trial of TCH346 in patients with ALS. Neurology 69(8):776-784
35. Gold J et al (2019) Safety and tolerability of Triumeq in amyotrophic lateral sclerosis: the Lighthouse trial. Amyot Lateral Scler Frontotemp Degen 20(7-8):595-604

36. Hammer EM et al (2008) Validity of the ALS-Depression-Inventory (ADI-12) - a new screening instrument for depressive disorders in patients with amyotrophic lateral sclerosis. J Affect Disord 109(1-2):213-219

37. Beck AT et al (1961) An inventory for measuring depression. Arch Gen Psychiatry 4(6):561-571

38. Sharp R (2015) The Hamilton rating scale for depression. Occup Med 65(4):340-340

39. Nilsson ME et al (2013) Columbia-suicide severity rating scale scoring and data analysis guide. CSSRS Scoring 2:1-13

40. Zigmond AS, Snaith RP (1983) The hospital anxiety and depression scale. Acta Psychiatr Scand 67(6):361-370

41. Cummings JL et al (1994) The Neuropsychiatric Inventory: comprehensive assessment of psychopathology in dementia. Neurology 44(12):2308-2308

42. Wang Y-P, Gorenstein C (2013) Assessment of depression in medical patients: a systematic review of the utility of the Beck Depression Inventory-II. Clinics 68(9):1274-1287

43. Mottram P, Wilson K, Copeland J (2000) Validation of the Hamilton Depression Rating Scale and Montgommery and Asberg Rating Scales in terms of AGECAT depression cases. Internat J Geriat Psych 15(12):1113-1119

44. Gibbons CJ et al (2011) Rasch analysis of the hospital anxiety and depression scale (HADS) for use in motor neurone disease. Health Quality life Outcomes 9(1):82

45. Posner $\mathrm{K}$ et al (2011) The Columbia-Suicide severity rating scale: initial validity and internal consistency findings from three multisite studies with adolescents and adults. Am J Psychiatry 168(12):1266-1277

46. Giddens JM, Sheehan KH, Sheehan DV (2014) The ColumbiaSuicide Severity Rating Scale (C-SSRS): Has the "gold standard" become a liability? Innov Clin Neurosci 11(9-10):66

47. Kaufer DI et al (2000) Validation of the NPI-Q, a brief clinical form of the Neuropsychiatric Inventory. J Neuropsyc Clin Neurosci 12(2):233-239

48. Lai CK (2014) The merits and problems of Neuropsychiatric Inventory as an assessment tool in people with dementia and other neurological disorders. Clin Interv Aging 9:1051

49. Woolley SC et al (2010) Detecting frontotemporal dysfunction in ALS: utility of the ALS Cognitive Behavioral Screen (ALSCBSTM). Amyot Lateral Scler 11(3):303-311

50. Abrahams $S$ et al (2014) Screening for cognition and behaviour changes in ALS. Amyot Lateral Scler Frontotemp Degen 15(1-2):9-14

51. Nasreddine ZS et al (2005) The montreal cognitive assessment, MoCA: a brief screening tool for mild cognitive impairment. J Am Geriatr Soc 53(4):695-699

52. Mathuranath P et al (2000) A brief cognitive test battery to differentiate Alzheimer's disease and frontotemporal dementia. Neurology 55(11):1613-1620

53. Murphy J, Ahmed F, Lomen-Hoerth C (2015) The UCSF screening exam effectively screens cognitive and behavioral impairment in patients with ALS. Amyot Lateral ScleR Frontotemp Degen 16(1-2):24-30

54. Wechsler D (1958) The measurement and appraisal of adult intelligence MD. Williams and Wilkins, USA

55. Glasmacher S (2020) The prevalence of multimorbidity and its impact on prognosis in motor neuron disease. The University of Edinburgh, Edinburgh

56. Mioshi E, Roberts R, Hornberger M (2015) Neuropsychiatric symptoms and survival in amyotrophic lateral sclerosis: a missing link? Neurodegen Dis Manag 5(2):89-91 
57. Phukan J, Pender NP, Hardiman O (2007) Cognitive impairment in amyotrophic lateral sclerosis. Lancet Neurol 6(11):994-1003

58. Hodgins F, Mulhern S, Abrahams S (2019) The clinical impact of the Edinburgh Cognitive and Behavioural ALS Screen (ECAS) and neuropsychological intervention in routine ALS care. Amyot Lateral Scler Frontotemp Degen 1:1-8

59. Niven E et al (2015) Validation of the Edinburgh Cognitive and Behavioural Amyotrophic Lateral Sclerosis Screen (ECAS): a cognitive tool for motor disorders. Amyot Lateral Scler Frontotemp Degen 16(3-4):172-179

60. Mitsumoto H et al (2014) ALS Multicenter Cohort Study of Oxidative Stress (ALS COSMOS): study methodology, recruitment, and baseline demographic and disease characteristics. Amyot Lateral Scler Frontotemp Degen 15(3-4):192-203

61. Murphy J et al (2016) Cognitive-behavioral screening reveals prevalent impairment in a large multicenter ALS cohort. Neurology 86(9):813-820

62. Woolley $\mathrm{S}$ et al (2018) Longitudinal screening detects cognitive stability and behavioral deterioration in ALS patients. Behav Neurol 2:18

63. Crockford C et al (2018) ALS-specific cognitive and behavior changes associated with advancing disease stage in ALS. Neurology 91(15):e1370-e1380
64. Elamin M et al (2013) Cognitive changes predict functional decline in ALS: a population-based longitudinal study. Neurology 80(17):1590-1597

65. Abrahams S, Leigh P, Goldstein L (2005) Cognitive change in ALS: a prospective study. Neurology 64(7):1222-1226

66. Atassi $\mathrm{N}$ et al (2011) Depression in amyotrophic lateral sclerosis. Amyot Lateral Scler 12(2):109-112

67. Mioshi E et al (2006) The Addenbrooke's Cognitive Examination Revised (ACE-R): a brief cognitive test battery for dementia screening. Internat J Geriat Psych Life Allied Sci 21(11):1078-1085

68. Osborne RA et al (2014) Screening for frontal lobe and general cognitive impairment in patients with amyotrophic lateral sclerosis. J Neurol Sci 336(1-2):191-196

69. Kertesz A et al (2000) The Frontal Behavioral Inventory in the differential diagnosis of frontotemporal dementia. J Internat Neuropsychol Soc 6(4):460-468

70. Dick J et al (1984) Mini-mental state examination in neurological patients. J Neurol Neurosurg Psychiatry 47(5):496-499

71. Moher D, Liberati A, Tetzlaff J, Altman DG, The PRISMA Group (2009). Preferred Reporting Items for Systematic Reviews and Meta-Analyses: The PRISMA Statement. PLoS Med 6(7): e1000097.https://doi.org/10.1371/journal.pmed1000097 